\title{
Light enhanced calcification in Stylophora pistillata: effects of glucose, glycerol and oxygen
}

Zooxanthellate corals have long been known to calcify faster in the light than in the dark, however the mechanism underlying this process has been uncertain. Here we tested the effects of oxygen under controlled pCO2 conditions and fixed carbon sources on calcification in zooxanthellate and bleached microcolonies of the branching coral Stylophora pistillata. In zooxanthellate microcolonies, oxygen increased dark calcification rates to levels comparable to those measured in the light. However in bleached microcolonies oxygen alone did not enhance calcification, but when combined with a fixed carbon source (glucose or glycerol), calcification increased. Respiration rates increased in response to oxygen with greater increases when oxygen is combined with fixed carbon. ATP content was largely unaffected by treatments, with the exception of glycerol which decreased ATP levels. 
1 Light enhanced calcification in Stylophora pistillata: effects of glucose, glycerol and oxygen

2

3 Michael Holcomb*, Eric Tambutté, Denis Allemand, Sylvie Tambutté

4 Centre Scientifique de Monaco

58 Quai Antoine 1er

6 MC-98000 Monaco

7

8 *Corresponding author current address:

9 Michael Holcomb

10 ARC Centre of Excellence in Coral Reef Studies

11 School of Earth and Environment \& Oceans Institute

12 The University of Western Australia

1335 Stirling Highway M004

14 Crawley, WA 6009 Australia

15 email: mholcomb3051@gmail.com 


\section{Abstract}

17 Zooxanthellate corals have long been known to calcify faster in the light than in the dark,

18 however the mechanism underlying this process has been uncertain. Here we tested the effects of

19 oxygen under controlled $\mathrm{pCO}_{2}$ conditions and fixed carbon sources on calcification in

20 zooxanthellate and bleached microcolonies of the branching coral Stylophora pistillata. In

21 zooxanthellate microcolonies, oxygen increased dark calcification rates to levels comparable to

22 those measured in the light. However in bleached microcolonies oxygen alone did not enhance

23 calcification, but when combined with a fixed carbon source (glucose or glycerol), calcification

24 increased. Respiration rates increased in response to oxygen with greater increases when oxygen

25 is combined with fixed carbon. ATP content was largely unaffected by treatments, with the

26 exception of glycerol which decreased ATP levels.

\section{Introduction}

28 Rising ocean temperatures and declining $\mathrm{pH}$ have received considerable attention in recent years (e.g. Hoegh-Guldberg et al., 2007; McCulloch et al., 2012). Among the major concerns are the impacts on coral reefs, particularly on corals themselves. As temperatures rise, bleaching events (the loss of symbiotic zooxanthellae) become more frequent and severe, reducing the ability of the coral to cope with other stressors, leading to the loss of coral reefs (e.g. McWilliams et al., 2005). Rising $\mathrm{CO}_{2}$ levels further compound the problem by reducing aragonite saturation state and potentially calcification (e.g. Langdon and Atkinson 2005; Holcomb et al., 2010).

Central to our understanding of the response of corals to changing environmental conditions is an understanding of the role the symbiotic zooxanthellae play in coral calcification. It has long been established that calcification rates increase in zooxanthellate corals during periods in which photosynthesis is occurring (Yonge, 1931), a process known as light-enhanced calcification (e.g. Vandermeulen et al., 1972; Gattuso et al., 1999). Comparisons of facultatively symbiotic corals with and without zooxanthellae similarly show increased calcification in the presence of symbionts (Jacques et al., 1983). Yet, comparisons of zooxanthellate corals to azooxanthellate corals show that some azooxanthellate corals can grow just as rapidly (Marshall, 1996;

43 Mortensen and Rapp, 1998), bleached corals can continue calcifying for some time at rates

44 similar to those of unbleached corals (Rodrigues and Grottoli, 2006), in corals such as acroporids, 45 the fastest growing regions are largely azooxanthellate (Pearse and Muscatine 1971), and light 
46 does not necessarily stimulate calcification in zooxanthellate corals (e.g. Rinkevich and Loya,

47 1984). Thus, it is not clear that symbionts per se enhance calcification.

48 There are several mechanisms which could be responsible for the increase in calcification

49 generally associated with symbiosis (for reviews see: Gattuso et al., 1999; Allemand et al., 2011;

50 Tambutté et al., 2011). Calcification could increase due to the drawdown in $\mathrm{CO}_{2}$ as a direct result

51 of photosynthesis, leading to increased $\mathrm{pH}$, shifting the dominate $\mathrm{CO}_{2}$ species from bicarbonate

52 to carbonate and increasing the saturation state (Kawaguti and Sakumoto, 1948). Other likely

53 mechanisms by which calcification could be increased include the use of fixed carbon from

54 photosynthesis as fuel to increase ion pumping and elevate saturation state (Goreau, 1959), or the

55 use of fixed carbon for organic matrix synthesis, which may facilitate aragonite precipitation

56 (Young et al., 1971). Oxygen produced by the zooxanthellae may relieve internal hypoxia and

57 thus enhance calcification (Rinkevich and Loya, 1984; Rands et al., 1992, Nakamura et al.,

58 2013). Or symbionts may remove compounds which inhibit calcification or metabolism (e.g.

59 Goreau, 1961; Vandermuelen and Muscatine, 1974).

60 Though numerous studies have examined the production of fixed carbon by zooxanthellae and 61 suggested that various forms of fixed carbon (glycerol (Muscatine, 1967), glucose (Burriesci et al., 2012), among other compounds (e.g. Whitehead and Douglas, 2003)) are translocated to the coral host, the role of fixed carbon specifically in calcification has received little attention.

64 Various carbon compounds are known to be taken up by corals. Stephens $(1960,1962)$, and

65 Lewis and Smith (1971) demonstrated that corals have the ability to take up fixed carbon compounds supplied exogenously. Stephens (1962) suggested that a glucose concentration of $\sim 80 \mu \mathrm{M}$ is sufficient for glucose uptake to balance respiration in Fungia. Oku et al. $(2003 \mathrm{a}, \mathrm{b})$ claimed corals have the ability to incorporate a range of exogenous sugars into their tissues, and that supplying sugars exogenously can improve the survival of bleached corals. Thus, exogenous fixed carbon may substitute for that provided by zooxanthellae.

The effect of fixed carbon supplementation on calcification has been examined in five studies. Taylor (1977) showed that fixed carbon compounds supplied exogenously are transported to the regions of most rapid growth. Vandermeulen and Muscatine (1974) and Chalker (1975) exposed corals in the light and in the dark to glucose, glycerol and alanine. Calcification rates were either unchanged or declined as a result of exposure to fixed carbon sources at concentrations from 10 $\mu \mathrm{M}-10 \mathrm{mM}$. A similar result was found by Al-Horani et al. (2007) for both glucose and feeding 
77 with Artemia. In contrast, Colombo-Pallotta et al. (2010) found that in bleached corals, glycerol could stimulate calcification, though not in zooxanthellate corals. Such results suggest that fixed carbon by itself is not generally limiting the calcification process.

In addition to fixed carbon, zooxanthellae also provide oxygen to the coral host. Several studies have documented the daily cycle in dissolved oxygen levels adjacent to the coral tissue, with hyperoxia persisting for much of the day, and hypoxia persisting for much of the night (e.g. Rands et al., 1992; Shashar et al., 1993; Marshall and Clode, 2003; Agostini et al., 2009). Respiration and calcification rates are linked to this cycle in oxygen saturation, with lower rates at reduced oxygen levels (Rinkevich and Loya, 1984; Shick, 1990; Al-Horani et al., 2007) and increased calcification rates under elevated oxygen (Colombo-Pallotta et al., 2010; Wijgerde et al., 2012, Nakamura et al., 2013). In both the studies of Vandermeulen and Muscatine (1974) and Chalker (1975), corals were incubated in unstirred, un-aerated containers, thus any potential benefit from the supplied carbon sources may have been masked by oxygen limitation. Under normal conditions, photosynthate is supplied and oxygen levels are elevated by photosynthesis, thus it may be the combination of oxygen and fixed carbon that allow the coral to respire and 92 calcify faster.

A lack of, or insufficient, flow may be an important factor limiting the potential benefits of fixed carbon in early experiments. Corals, like many benthic organisms, depend upon water movement for their supply of nutrients, food, and waste removal. Water flow plays a major role in determining the diffusive boundary layers surrounding corals, affecting transport rates of $\mathrm{O}_{2}, \mathrm{CO}_{2}$, nutrients, etc. likely affecting all aspects of coral physiology (Dennison and Barnes 1988; Atkinson and Bilger 1992; Kuhl et al., 1995; Nakamura and van Woesik 2001). Respiration in particular may be limited by the diffusion of oxygen under stagnant or low-flow conditions (Shick 1990; Kuhl et al., 1995), which would in-turn limit energy availability to other processes, such as calcification. Thus adequate flow is likely critical if any benefit is to be seen to supplementation with fixed carbon.

103 Given that respiration and calcification rates respond to elevated oxygen levels, dark calcification 104 may indeed be energy limited due to insufficient oxygen to maintain oxidative phosphorylation.

105 Fixed carbon availability may also limit calcification if sufficient oxygen is available. Thus, 106 elevated oxygen levels in combination with fixed carbon supplementation may be sufficient to 107 increase dark calcification rates to levels comparable to light calcification rates. The primary 
energy carrier used to convert energy derived from respiration into ion pumping and other energy

109 requiring activities is adenosine triphosphate (ATP), thus energy limitation may be reflected in

110 cellular ATP content. Here combinations of different fixed carbon sources and concentrations

111 and elevated oxygen levels were tested on zooxanthellate and bleached microcolonies of the

112 branching coral Stylophora pistillata to determine whether oxygen limitation or a combination of

113 oxygen and fixed carbon limitation can explain light enhanced calcification. In addition to

114 calcification, respiration and ATP were measured to provide insight into the potential underlying

115 processes.

\section{Materials \& Methods}

118 Experimental organisms

119 Colonies of the branching coral Stylophora pistillata were maintained in the laboratories of the

120 Centre Scientifique de Monaco in flow-through aquaria receiving Mediterranean seawater $(\mathrm{S}=38)$

121 heated to $25^{\circ} \mathrm{C}$. Experimental microcolonies were prepared as described by Al-Moghrabi et al

122 (1993) and Ferrier-Pagès et al (2003), composed of $\sim 2 \mathrm{~cm} \mathrm{x} \sim 1 \mathrm{~cm}$ terminal portions of branches

123 on nylon monofilament line. Microcolonies were used after at least three weeks of recovery,

124 allowing tissue to fully cover the cut skeleton. Lighting was provided by JBL Marin Day T5

125 bulbs providing an irradiance of $\sim 195 \mu \mathrm{mol}$ photons $\mathrm{m}^{-2} \mathrm{~s}^{-1}$ at the position of the microcolonies

126 with a $12 \mathrm{~h}$ light/dark cycle. To prepare bleached microcolonies, microcolonies were maintained

127 in the dark for a minimum of six weeks prior to use, at which point microcolonies appeared pure

128 white. Microcolonies were fed twice a week with newly hatched Artemia sp. A subset of

129 microcolonies were weighed periodically to estimate growth rates (buoyant weight technique,

130 Jokiel et al. 1978; Davies 1989).

131

132 Experimental incubations 
133 Exposures to treatment conditions, calcification, and respiration rate measurements were carried

134 out in $250 \mathrm{ml}$ Erlenmeyer flasks (made of borosilicate glass). Flasks were sealed using

135 transparent acrylic stoppers. A small hole in the center of the acrylic stopper allowed a

136 microcolony to be suspended in the center of the flask; a rubber stopper was used to seal the hole

137 once the microcolony had been placed level with the $200 \mathrm{ml}$ mark (Supplemental Figure S1).

138 Preliminary experiments showed oxygen influx into nitrogen sparged seawater and oxygen efflux

139 from oxygen sparged seawater were negligible with this sealing system. Flasks were placed on a

140 multiposition magnetic stir plate and stirred at $145 \mathrm{rpm}$ with teflon coated stir bars. Different stir

141 bar sizes $(7.8 \times 39.2 \mathrm{~mm}, 5.9 \times 15 \mathrm{~mm}$, and $4.5 \times 11.95 \mathrm{~mm}$ - values are average measured

142 diameter and length, the manufacturer's stated size was generally slightly larger) were tested

143 initially (Fig. 1), different stirring speeds were tested as well (data not shown, see supplemental

144 material). Flasks were held within a constant temperature bath set at $25^{\circ} \mathrm{C}$. Incubations were

145 carried out either in the dark or under $\sim 195 \mu \mathrm{mol}$ photons $\mathrm{m}^{-2} \mathrm{~s}^{-1}$ provided by JBL Marin Day T5

146 bulbs. Microcolonies were starved for at least two days prior to being used in experiments to

147 reduce nutrient efflux. All dark incubations for zooxanthellate colonies were started in the

148 morning such that microcolonies had been pre-conditioned to dark conditions for $12 \mathrm{hr}$ prior to

149 the start of experiments. Light incubations were carried out during normally lit hours. Corals

150 were maintained under treatment conditions for at least $20 \mathrm{~min}$ prior to starting the experiment to

151 allow the coral to acclimate to treatment conditions. All seawater used for incubations was

152 passed through two $0.45 \mu \mathrm{m}$ membrane filters prior to use. The seawater mass present in each

153 incubation was estimated based on the mass of seawater held by each incubation chamber

154 without a coral and the displacement volume of the coral skeleton calculated from skeletal dry

155 weight and assuming a density of $2.9 \mathrm{~g} / \mathrm{cm}^{3}$. For each experimental run, in addition to treatment

156 incubations, seawater only and treatment seawater incubations were carried out to check for 
157 background changes and corals not exposed to treatment conditions were included as well to

158 check for day-to-day variations in growth/metabolic rates. Following incubations, water from a

159 subset of flasks which had previously contained corals was pooled and used for an additional

160 incubation (without coral) to assess the potential for microbial growth in the treatment seawater

161 to impact the measured values. Dark incubations of corals generally resulted in a $\sim 14 \%$ decline

162 in oxygen and a $\sim 4 \%$ decline in alkalinity by the end of the incubation. In some instances (for

163 bleached microcolonies), the change in alkalinity was below the resolution of the measurement

164 method, calcification data for such incubations were discarded.

165

166 Water chemistry

167 Oxygen

168 Experimental oxygen and $\mathrm{CO}_{2}$ levels were set by bubbling seawater held at $25^{\circ} \mathrm{C}$ with

169 humidified air or mixed gas, the composition of the mixed gas was set using mass flow

170 controllers to mix ambient air, oxygen, and $\mathrm{CO}_{2}$ to achieve $\sim 2 \mathrm{x}$ ambient $\mathrm{pO}_{2}$ at ambient $\mathrm{pCO}_{2}$.

$171 \mathrm{CO}_{2}$ levels were verified using a Licor $6262 \mathrm{CO}_{2}$ analyzer. Oxygen (\% saturation) was measured

172 using a fiber optic oxygen measurement system (PreSens) with Pst3 sensors mounted on the

173 inside of each flask. Sensors were calibrated with air (100\%) and $\mathrm{N}_{2}(0 \%)$ sparged seawater, a

174 linear response was assumed. Atmospheric pressure was recorded at the time each experiment

175 was performed. Oxygen concentrations were calculated as follows. The oxygen concentration

176 for air saturated $(100 \%)$ seawater at the experimental salinity and pressure was calculated using

177 data from Benson and Krause (1984) as fit by equation 8 of Garcia and Gordon (1992), the first

$178 \mathrm{~A}_{3}$ term was ignored. Concentrations calculated in this manner are for $1 \mathrm{~atm}$ total pressure,

179 values were corrected for the measured atmospheric pressure and used to convert percent

180 saturation measurements to concentrations. 
182 Carbonate chemistry

183 Alkalinity samples were collected at the start and end of each experiment in pre-cleaned $20 \mathrm{ml}$

184 scintillation vials and stored at $4{ }^{\circ} \mathrm{C}$ till measured. Semi-automated titrations with $0.03 \mathrm{~N} \mathrm{HCl}$

185 (containing $41 \mathrm{~g} / \mathrm{L} \mathrm{NaCl}$ ) were carried out on $\sim 4 \mathrm{~g}$ replicated samples using a Metrohm Titrando

186808 dosimat. Certified reference material (supplied by the laboratory of Andrew Dickson,

187 Scripps Institute of Oceanography) and an internal seawater standard were run each time samples

188 were measured, alkalinity was calculated via regression per Holcomb et al. (2012).

189 Samples for $\mathrm{pH}$ measurement were collected in $20 \mathrm{ml}$ syringes, capped, and kept in a $25^{\circ} \mathrm{C}$ water

190 bath until measured. An initial sample was injected into a $10 \mathrm{~cm}$ fiber optic flow cell for

191 collecting the reference spectrum, then $\sim 1 \mu 1$ of a $1.47 \mathrm{mM}$ meta Cresol Purple (Acros

192199250050 lot: A0264321) solution was added per ml seawater in the syringe using a micrometer

193 syringe (Gilmont) to inject and mix the mCP. The solution was then injected into the flow cell

194 and the $\mathrm{pH}$ measured, calculations followed DOE (1994).

195 Alkalinity, ammonia, and $\mathrm{pH}$ were then used to estimate calcification assuming calcification

196 alters alkalinity by 2 moles per mole $\mathrm{CaCO}_{3}$ produced, ammonia was assumed to increase

197 alkalinity by an amount equal to its concentration. Carbonate chemistry parameters were

198 calculated using CO2Sys (van Heuven et al., 2009), additional species contributing to alkalinity

199 were included as appropriate.

200

201 Fixed carbon

202 All incubations with fixed carbon substrates included antibiotics (35 IU penicillin, $0.035 \mathrm{mg}$

203 streptomycin per $\mathrm{ml}$ ) and antibiotics were included in the associated control incubations. The

204 effects of this antibiotic concentration on calcification and respiration were tested as well.

205 Glucose or glycerol was added as a concentrated stock solution. Target concentrations were $\sim 1$ 
$206 \%$ (120 mM) glycerol, $1 \mathrm{mM}$ glycerol, $1 \mathrm{mM}$ glucose, and $0.02 \mathrm{mM}$ glucose. Concentrations

207 were chosen based on the works of Whitehead and Douglas (2003) and Colombo-Pallotta et al.

208 (2010). Concentrations of each respiratory substrate were verified at the start and end of each

209 incubation using one of the following kits, protocols were modified slightly to improve results in

210 seawater matrices: d-glucose kit (Megazyme) for glucose, glycerol GK kit (Megazyme) for

211 glycerol. Measured concentrations were: 110 - $130 \mathrm{mM}$ and 1 - $1.4 \mathrm{mM}$ for glycerol, $0.9-1 \mathrm{mM}$

212 and $0.019-0.021 \mathrm{mM}$ for glucose. Concentrations of all fixed carbon compounds changed by

213 less than $10 \%$ during the incubations, except for the $0.02 \mathrm{mM}$ glucose treatment for which

214 concentration declined by $\sim 40 \%$ by the end of the incubation, which is consistent with estimates

215 of the uptake of fixed carbon substrates (Stephens 1960; Whitehead and Douglas 2003).

217 Nutrients

218 Ammonia and phosphate concentrations were measured at the start and end of a subset of

219 incubations using a Proxima autoanalyzer (Alliance Instruments) following the manufactures

220 recommended protocols. No nutrient release was detected for zooxanthellate microcolonies, only

221 for bleached microcolonies were nutrient releases measureable and thus alkalinity data corrected

222 for changes in nutrient concentrations.

223

224 ATP

225 ATP was extracted with sulfuric acid following a protocol modified from Fang et al. (1987;

226 1989). Microcolonies were placed in $0.6 \mathrm{~N}$ sulfuric acid (kept on water/ice prior to use) and

227 placed immediately in a sonicator (Branson 200 Ultrasonic Cleaner) filled with water/ice.

228 Samples were sonicated for $15 \mathrm{~min}$, tubes with microcolonies re-weighed, and a sample of the

229 extract transferred to a $1.5 \mathrm{ml}$ polypropylene tube (Eppendorf) and stored at $-80{ }^{\circ} \mathrm{C}$ until

230 measured. See supplementary materials for a comparison of this method with other techniques. 
232 ATP measurements were made using a luciferin/luciferase based ATP detection kit (Roche ATP

233 Bioluminescence Assay Kit HS II) with light emission measured using either a Lumat 9507 or

2349508 luminometer (Berthold), and concentrations calculated based on standard additions. A

235 detailed protocol is included in the supplemental materials.

237 Normalizations:

238 Protein was extracted from the tissue following ATP extraction by adding $\mathrm{NaOH}$ to produce $\mathrm{a} \sim 1$

$239 \mathrm{~N} \mathrm{NaOH}$ solution which was held at $90{ }^{\circ} \mathrm{C}$ for $\sim 20 \mathrm{~min}$. Protein was measured using a Pierce

240 BCA protein assay kit; protein concentrations were calculated using standard addition (using

241 BSA as the standard).

242 Surface area was determined via the wax method of Stimson and Kinzie (1991). Normalization 243 data are summarized in the supplementary materials (Table S2).

245 Statistics

246 To calculate total protein and ATP per coral it was assumed that the internal water volume of the

247 microcolony equilibrated with the surrounding solution, thus the extract volume consisted of the

248 volume of the extraction solution added plus the volume of seawater added with the microcolony

249 (approximated by the change in weight of the tube upon addition of the coral minus the dry 250 weight of the coral).

251 ATP extracted from corals was normalized to surface area, protein, and skeletal dry weight and

252 compared using a one-way ANOVA. Measurements of calcification and respiration under

253 treatment conditions were normalized to measurements on the same coral under ambient (dark)

254 conditions, to account for day to day variations in rates, all rates were normalized to untreated

255 controls measured at the same time (per Holcomb et al., 2012), data were subsequently compared 
using ANOVA. When the overall ANOVA model showed a significant treatment effect,

257 treatments significantly different from each other were detected using Dunnett's multiple

258 comparison to compare treatments to controls. Residuals were plotted against predicted values

259 and on normal probability plots to assess violations of ANOVA assumptions. The SAS software

260 package was used for all statistical tests.

261

262 Results

263 Effects of stirring on physiological parameters

264 Several stirring rates and stir bar sizes were tested to establish appropriate flow rates for the

265 experimental incubations (Fig. 1). Significant differences were detected in dark respiration rates

266 among stirring treatments $\left(\mathrm{F}_{2,13}=18.68, \mathrm{p}=0.0002\right)$, with smaller stir bars being associated with

267 lower respiration rates. No significant differences in calcification were detected, though there

268 was an apparent trend toward higher dark calcification rates with larger stir bar sizes. A stirring

269 speed of $145 \mathrm{rpm}$ with a $39.2 \times 7.8 \mathrm{~mm}$ (manufacturers stated size: $40 \times 8 \mathrm{~mm}$ ) stir bar was

270 chosen for the experiments since it allowed maximal respiration and calcification rates while

271 maintaining normal polyp expansion (visually assessed, not quantified).

272

273 Effect of treatments on calcification

274 Dark calcification was significantly affected by treatment conditions $\left(\mathrm{F}_{7,125}=10.69, \mathrm{p}<0.0001\right.$ for 275 zooxanthellate and $\mathrm{F}_{6,38}=3.99, \mathrm{p}=0.0034$ for bleached microcolonies, Fig. $2 \mathrm{~A}, \mathrm{C}$ ). Exposure to 276 light or oxygen significantly $(\mathrm{p}<0.05)$ increased calcification of zooxanthellate microcolonies 277 relative to dark controls while $1 \%$ glycerol with oxygen led to a significant decline in dark 278 calcification (Fig. 2A). Treatment with glucose and oxygen or lower concentrations of glycerol

279 with oxygen was not associated with a significant change in dark calcification for zooxanthellate 280 microcolonies. In contrast, for bleached microcolonies light or oxygen alone had no effect but 
281 treatment with oxygen combined with fixed carbon increased dark calcification, with a significant

282 increase $(\mathrm{p}=0.0035)$ for the $1 \%$ glycerol plus oxygen treatment (Fig. 2C).

283

284 Effects of treatments on respiration

285 Respiration rates were significantly affected by treatment conditions $\left(F_{6,65}=26.96, p<0.0001\right.$ for

286 zooxanthellate and $\mathrm{F}_{6,43}=23.48, \mathrm{p}<0.0001$ for bleached microcolonies, Fig. $\left.2 \mathrm{~B}, \mathrm{D}\right)$. All

287 treatments (except antibiotics) were associated with higher oxygen consumption in the dark

$288(\mathrm{p}<0.05)$ for zooxanthellate microcolonies with the largest increases for corals treated with

289 oxygen and fixed carbon (Fig. 2B) (incubation in the light led to oxygen production, data were

290 not compared with dark incubations). Similarly in bleached microcolonies treatment with fixed

291 carbon combined with oxygen had the largest effect $(p<0.001)$ on respiration (Fig. 2D) (light had

292 no effect on respiration in bleached colonies).

293

294 Effect of treatments on ATP

295 Treatments significantly affected ATP levels in zooxanthellate microcolonies regardless of the

296 normalization procedure $\left(\mathrm{F}_{6,32}=3.18, \mathrm{p}=0.0146\right.$ for normalization to protein, $\mathrm{F}_{6,32}=6.41$,

$297 \mathrm{p}=0.0002$ for dry weight, $\mathrm{F}_{6,32}=5.71, \mathrm{p}=0.0004$ for surface area), with reduced ATP levels being

298 associated with glycerol (Fig. 3). For bleached microcolonies similar trends were observed,

299 however only for normalization to surface area was the $1 \%$ glycerol with oxygen treatment

300 significantly lower than control $\left(\mathrm{F}_{5,26}=3.84, \mathrm{p}=0.0097\right.$, pairwise $1 \%$ glycerol to control $\left.\mathrm{p}=0.011\right)$.

301

302 Discussion

303 Stirring

304 Flow limitation may in-part explain the wide range of estimates for 'light enhanced calcification'

305 (Gattuso 1999; Al-Horani et al., 2007). In the initial experiments with different sized stir bars 
306 (Fig. 1) light calcification and oxygen production remained nearly constant, while smaller stir

307 bars (and consequent reduced flow) were associated with declines in dark respiration and

308 calcification. If such trends extend to still lower flow regimes, as may be suggested by the larger

309 declines in dark calcification observed by Dennison and Barnes (1988) under unstirred

310 conditions, large differences in light $\mathrm{v}$ dark calcification could be generated by incubating corals

311 in static or poorly stirred containers. As suggested by experiments with elevated oxygen (Fig. 2),

312 and experiments under aerated versus un-aerated conditions (Rinkevich and Loya 1984), oxygen

313 limitation may be the primary factor responsible for reduced calcification in the dark. The effects

314 of oxygen limitation are likely to be amplified under low flow conditions due to the increased

315 thickness of the diffusive boundary layer (e.g. Kuhl et al., 1995), as has been established for

316 respiration (e.g. Shick 1990).

317

318 Calcification

319 For corals with intact symbiosis (zooxanthellate microcolonies), oxygen appears to be the

320 primary factor limiting dark calcification (Fig. 2A). A similar rate enhancement was seen with

321 both light and oxygen in zooxanthellate microcolonies, suggesting oxygen production by the

322 symbionts is the primary mechanism for light enhanced calcification. Similar observations have

323 been made previously (Colombo-Pallotta et al., 2010; Wijgerde et al., 2012), however earlier

324 studies have not monitored $\mathrm{pCO}_{2}$ when adjusting $\mathrm{pO}_{2}$, thus the possibility of changes in saturation

325 state being responsible for the reported increase in calcification could not be ruled out. Here

$326 \mathrm{pCO}_{2}$ has been controlled during oxygen manipulation to ensure that the observed effect is a

327 result of oxygen elevation and not concomitant degassing of $\mathrm{CO}_{2}$. In contrast to Wijgerde et al

328 (2012), we found no indication that oxygen tensions of $\sim 200 \%(\sim 400 \mu \mathrm{mol} / \mathrm{kg} \mathrm{sw})$ negatively

329 affected coral growth. Indeed it seems surprising that such a modest increase in external $\mathrm{pO}_{2}$ 
330 would be associated with substantial declines in calcification given that higher $\mathrm{pO}_{2}$ is present at

331 the surface of the coral tissue when photosynthesis is occurring (Shashar et al., 1993), and that

332 such conditions are usually associated with enhanced calcification e.g. light enhanced

333 calcification.

334 Oxygen alone is not sufficient to increase calcification, as seen in bleached microcolonies (Fig.

335 2C). A respiratory substrate must also be present to allow the coral to benefit from increased

336 oxygen tension. The precise nature of the respiratory substrate appears to be of less importance

337 than its concentration as suggested by an increase in calcification for both glucose and glycerol

338 which appears to be enhanced at high substrate concentrations. However, high concentrations of

339 fixed carbon in the seawater are not necessarily beneficial to calcification as glycerol

340 concentrations which enhanced calcification in bleached microcolonies reduced dark calcification

341 in zooxanthellate microcolonies (Fig 2; Colombo-Pallotta et al., 2010).

342 The similarity of the results of the current study and those of Colombo-Pallotta et al. (2010)

343 suggest that oxygen limitation in the dark for zooxanthellate corals is a common phenomenon,

344 affecting both branching (S. pistillata, current study), and massive corals (Montastraea faveolata,

345 Colombo-Pallotta et al., 2010). However, although oxygen may generally be limiting

346 calcification at night in zooxanthellate corals, there is likely a gradual depletion in respiratory

347 substrates over the course of the night and eventually respiratory substrates will become limiting

348 even for zooxanthellate corals. This may help to explain why declines in calcification with

349 prolonged dark incubations have been observed in some studies (Al-Horani et al., 2007) but not

350 others (Moya et al., 2006), and be partly responsible for the lack of an enhancement of

351 calcification in earlier studies of fixed carbon supplementation (Vandermeulen and Muscatine

352 1974; Chalker 1975). For corals in the natural environment, there is likely to be a high degree of

353 variability amongst corals as to whether fixed carbon or oxygen is limiting in the dark, depending

354 upon such factors as flow, light history, photosynthetic rates, etc. 
356 Respiration

357 Respiration was similarly affected by oxygen and fixed carbon for both zooxanthellate and

358 bleached microcolonies (Fig 2B, D), with increased rates at elevated $\mathrm{pO}_{2}$ and further increases

359 with added fixed carbon. Despite increases in respiration, calcification did not necessarily

360 increase, with different patterns being observed in bleached versus zooxanthellate microcolonies

361 (Fig. 2). Since treatments had different effects on calcification but similar effects on respiration

362 for zooxanthellate $\mathrm{v}$ bleached microcolonies, there could be fundamentally different processes

363 occurring e.g. additional fixed carbon stressing the carbon replete zooxanthellate microcolonies,

364 yet benefiting the fixed carbon limited bleached colonies, or use of additional fixed carbon (and

365 energy) in biosynthetic pathways for zooxanthellate microcolonies and respiration for bleached

366 colonies. However it is also possible that the additional fixed carbon is having similar effects for

367 both zooxanthellate and bleached corals. Since the oral tissue layers (which do not carry out

368 calcification) are most exposed to the surrounding environment, they are likely to be more

369 affected by changes in the composition of the external seawater. So oxygen and fixed carbon in

370 the seawater are likely to have a greater effect on the oral tissue layers than the aboral tissue

371 layers, thus the changes in respiration may reflect primarily the oral tissue layers. For

372 zooxanthellate microcolonies with their high respiration rates (Table S2) and greater tissue

373 thicknesses (assumed from a higher protein content per unit surface area in zooxanthellate

374 microcolonies relative to bleached (Table S2), which may be associated with a greater diffusion

375 distance through the tissue), increases in respiration in the oral tissue layers in response to fixed

376 carbon may reduce oxygen availability to the calicoblasts and thus reduce calcification

377 (alternatively the increased $\mathrm{CO}_{2}$ produced by respiration could generate similar patterns). In

378 bleached microcolonies, respiration rates are lower and the tissue thickness (protein content) is

379 reduced, thus the increase in respiration by oral tissue layers may be insufficient to restrict the 
oxygen supply to the calicoblasts, thus allowing the calicoblasts to benefit from the supply of

381 fixed carbon. Zooxanthellae are likely to be more effective than external substrates in enhancing

382 calcification due to the production of oxygen and fixed carbon within the coral tissue, and thus

383 closer to the calicoblasts. Though even photosynthesis may not be sufficient to completely

384 eliminate hypoxia in parts of the calicodermis, as suggested by low $\mathrm{pO}_{2}$ values measured within

385 some corals (Agostini et al., 2011), so hypoxia may still affect calcification even under light

386 conditions.

387 Estimates of gross photosynthesis which have been made by combining net oxygen release in the

388 light and oxygen consumption in the dark have long been known to be underestimates (Edmunds

389 and Davies 1988; Shick 1990). Our results suggest that light respiration is stimulated by both

390 oxygen and fixed carbon produced by photosynthesis, and, based on our observed stimulation,

391 respiration rates are likely to be at least $20 \%$ higher in the light than in the dark. Even greater

392 enhancements have been reported for short-term respiration measurements made immediately

393 after light incubations (Edmunds and Davies 1988; Colombo-Pallotta et al., 2010). However,

394 much of this enhancement of respiration may be due to respiration by the zooxanthellae, with a

395 relatively small enhancement in the animal host (Agostini et al., 2013).

397 ATP

398 Despite different fixed carbon sources having similar effects on respiration and calcification, 399 glucose and glycerol had markedly different effects on ATP (Fig. 3). Glycerol was associated

400 with reduced ATP levels while little change was observed for other treatment conditions.

401 Although it is not clear why such a difference is observed, it could be associated with high

402 concentrations of glycerol stressing the corals as reduced ATP levels have been associated with

403 stress events (Fang et al., 1991). Or it may reflect different pathways being used for glycerol

404 versus glucose (e.g. Whitehead and Douglas 2003), and the demands of those respective 
405 pathways on cellular ATP. Light $\mathrm{v}$ dark conditions appear to make relatively little difference in

406 ATP levels - here we measured slightly lower values in the light, while previously slightly higher

407 levels have been measured in the light (Al-Horani et al., 2003), in neither case were the

408 differences statistically significant, suggesting that corals generally regulate metabolic activities

409 to maintain stable ATP levels, though glycerol may perturb this balance (Fig. 3). ATP levels have

410 been suggested to be potentially useful indicators of coral health (Fang et al., 1991), however our

411 results suggest that such an interpretation is far from clear - calcification, which is also used as

412 an indicator of coral health, showed little relationship to ATP levels. However, ATP appears to be

413 a potential indicator of coral biomass. ATP normalized to protein was similar for zooxanthellate

414 and bleached microcolonies, but when normalized to either skeletal mass or surface area, ATP

415 was lower in bleached microcolonies, suggesting that ATP is closely linked to biomass as has

416 been observed in deep-sea corals (Hamoutene et al., 2008), and since tissue biomass is a potential

417 indicator of coral health, ATP may be similarly useful.

418 Due to the nature of the measurements, we cannot, however, rule out a role for ATP levels in

419 controlling calcification rates. Our measurements estimate total ATP and not the ATP content of

420 the calicoblastic cells, nor the turn-over of ATP within the calicoblasts. Thus though the ATP

421 content of the full tissue layer does not track calcification, we cannot assess whether ATP levels

422 within different cell layers respond differently to treatments and what the ATP content of the

423 calicoblasts may be.

\section{Environmental context}

426 Although aquarium conditions are far removed from natural environmental conditions in

427 many respects - with corals often experiencing constant temperatures, flow regimes, and light

428 intensities under aquarium conditions, many of the parameters measured agree well with

429 measurements made on corals taken from natural environments. ATP levels for a variety of 
corals collected from the wild were reported to range from 8.2-52.6 $\mu \mathrm{g} / \mathrm{g}$ (Fang et al., 1991),

431 our measurements $(\sim 9.3-46.8 \mu \mathrm{g} / \mathrm{g})$ fall well within this range, however Fang et al. (1991) did

432 not report values for $S$. pistillata. Our respiration rate of $12.5 \mu \mathrm{mol} \mathrm{O} / \mathrm{d} / \mathrm{cm}^{2}$ (for zooxanthellate

433 control corals) falls within the range measured in S. pistillata in the field: $0.5-16.6 \mu$ mol

$434 \mathrm{O}_{2} / \mathrm{d} / \mathrm{cm}^{2}$ (Mass et al., 2007). Calcification rates $\left(23.7 \mu \mathrm{mol} \mathrm{CaCO}_{3} / \mathrm{d} / \mathrm{cm}^{2}\right.$ for zooxanthellate

435 control corals), were however higher than recently reported in the field for S. pistillata $-0.24-9.6$

$436 \mu \mathrm{mol} \mathrm{CaCO}_{3} / \mathrm{d} / \mathrm{cm}^{2}$ (Mass et al., 2007). However, in other species, higher calcification rates have

437 been reported during the light: $24 \mu \mathrm{mol} \mathrm{CaCO}_{3} / \mathrm{d} / \mathrm{cm}^{2}$ (Schneider et al., 2009), $88 \mu \mathrm{mol}$

$438 \mathrm{CaCO}_{3} / \mathrm{d} / \mathrm{mg}$ protein (Dennison and Barnes 1988), and in the dark: $44 \mu \mathrm{mol} \mathrm{CaCO} 3 / \mathrm{d} / \mathrm{mg}$ protein

439 (Dennison and Barnes 1988) versus our $10.2 \mu \mathrm{mol} \mathrm{CaCO}_{3} / \mathrm{d} / \mathrm{mg}$ protein. Despite the differences

440 between aquarium and natural conditions, for the range of physiological parameters measured,

441 values fall within the range encountered in the natural environment. Thus, results from the

442 current laboratory experiment likely apply to the natural environment, though with the diversity

443 of species, growth forms, and environmental conditions found in nature, it is difficult to assess

444 how common oxygen or fixed carbon limitation may be in corals growing under natural

445 conditions.

446

447 Conclusions

448 Oxygen limitation plays a role in explaining reduced calcification rates during dark periods for

449 scleractinian corals. Factors such as flow rate and tissue structure likely contribute to the degree

450 of oxygen limitation and thus influence 'light enhanced calcification'. Fixed carbon can also be

451 limiting, as was the case for bleached microcolonies. However changes in total ATP in the tissue

452 did not reflect changes in calcification, but rather changed in response to the form of fixed 
453 carbon. This suggests that any regulation of calcification by energy availability occurs via a 454 pathway which is not responding directly to the total ATP level in the tissue.

455

456 


\section{Acknowledgments}

458 We would like to thank our colleagues for assistance and fruitful discussions, particularly R.

459 Grover, S. Sikorski, C. Rottier, C. Godinot, M. Naumann, N. Segonds, D. Desgre, A. Venn, N.

460 Techer, C. Ferrier-Pagès, and E. Elia. We also thank G. Gaetani (Woods Hole Oceanographic

461 Institution) and M. McCulloch (University of Western Australia) for the use of equipment.

\section{References}

Agostini S, Suzuki Y, Higuchi T, Casareto BE, Yoshinaga K, Nakano Y, Fujimura H. 2011. Biological and chemical characteristics of the coral gastric cavity. Coral Reefs 31:147-156. system activity in symbiotic corals and its link to calcification. Aquatic Biology 18:125-139.

Al-Horani FA, Al-Moghrabi SM, de Beer D. 2003. The mechanism of calcification and its relation to photosynthesis and respiration in the scleractinian coral Galaxea fascicularis. Marine Biology 142: 419-426.

Al-Horani FA, Tambutté É, Allemand D. 2007. Dark calcification and the daily rhythm of calcification in the scleractinian coral, Galaxea fascicularis. Coral Reefs 26:531-538.

Al-Moghrabi S, Allemand D, Jaubert J. 1993. Valine uptake by the scleractinian coral Galaxea fascicularis: characterization and effect of light and nutritional status. Journal Comparative Physioliogy B 163: 355-362.

Allemand D, Ferrier-Pagès C, Furla $P$, Houlbrèque F, Puverel S, Reynaud S, Tambutté É, Tambutté S, Zoccola D. 2011. Biomineralization in reef-building corals : from molecular mechanisms to environnemental control. CR Acad Sc Paris Palévol 3:453-467.

Benson BB, Krause JD. 1984. The concentration and isotopic fractionation of oxygen dissolved in freshwater and seawater in equilibrium with the atmosphere. Limnology Oceanography 29:620-632.

Burriesci MS, Raab TK, Pringle JR. 2012. Evidence that glucose is the major transferred metabolite in dinoflagellate-cnidarian symbiosis. Journal of Experimental Biology 215:34673477.

Chalker BE. 1975. Calcification, metabolism, and growth by the staghorn coral, Acropora cervicornis (Lamarck). Thesis; University of Miami.

Chida J, Yamane K, Takei T, Kido H. 2012. An efficient extraction method for quantitation of adenosine triphosphate in mammalian tissues and cells. Anal Chim Acta 727:8-12.

Cohen AL, Holcomb M. 2009. Why corals care about ocean acidification. Oceanography 22: 118-127.

Colombo-Pallotta MF, Rodríguez-Román A, Iglesias-Prieto R. 2010. Calcification in bleached and unbleached Montastraea faveolata: evaluating the role of oxygen and glycerol. Coral Reefs 29:899-907.

Crossland CJ, Barnes DJ. 1974. The role of metabolic nitrogen in coral calcification. Marine Biology 28: 325-332.

Davies PS. 1989. Short-term growth measurements of corals using an accurate buoyant weighing technique. Marine Biology 101:389-395. 
Dennison WC, Barnes DJ. 1988. Effect of water motion on coral photosynthesis and calcification. Journal Experimental Marine Biology Ecology 115:67-77.

DOE. 1994. Handbook of methods for the analysis of the various parameters of the carbon dioxide system in sea water version 2

Edmunds PJ. 2011. Zooplanktivory ameliorates the effects of ocean acidification on the reef coral Porites spp. Limnology Oceanography 56: 2402-2410.

Edmunds PJ, Davies S. 1988. Post-illumination stimulation of respiration rate in the coral Porites porites. Coral Reefs 7:7-9.

Falter JL, Atkinson MJ, Coimbra CFM. 2005. Effects of surface roughness and oscillatory flow on the dissolution of plaster forms: Evidence for nutrient mass transfer to coral reef communities. Limnology Oceanography 50: 246-254.

Fang L-S, Chen Y-W, Chen C-S. 1991. Feasibility of using ATP as an index for environmental stress on hermatypic coral. Marine Ecology Progress Series 70: 257-262.

Fang L-S, Chen Y-WJ, Chen C-S. 1989. Why does the white tip of stony coral grow so fast without zooxanthellae? Marine Biology 103: 359-363.

Fang L-S, Chen Y-WJ, Soong KY. 1987. Methodology and measurement of ATP in coral. Bulletin Marine Science 41: 605-610.

Ferrier-Pages C, Witting J, Tambutte E, Sebens KP. 2003. Effect of natural zooplankton feeding on the tissue and skeletal growth of the scleractinian coral Stylophora pistillata. Coral Reefs 22: $229-240$.

Garcia HE, Gordon LI. 1992. Oxygen solubility in seawater: Better fitting equations. Limnology Oceanography 37:1307-1312.

Gattuso JP, Allemand D, Frankignoulle M. 1999. Photosynthesis and calcification at cellular, organismal and community levels in coral reefs: a review of interactions and control by carbonate chemistry. American Zoologist 39: 160-183.

Gladfelter EH. 1982. Skeletal development in Acropora cervicornis: I. patterns of calcium carbonate accretion in the axial corallite. Coral Reefs 1:45-51.

Goreau TF. 1959. The physiology of skeleton formation in corals I. a method for measuring the rate of calcium deposition by corals under different conditions. Biological Bulletin 116:59-75.

Goreau TF. 1961. On the relation of calcification to primary productivity in reef building organisms. In Lenhoff, HM, Loomis, WH ed. The biology of hydra and some other coelenterates. 269-285.

Hamoutene D, Burt K, Samuelson S, Wareham V, Miller-Banoub J. 2008. Adenosine triphosphate (ATP) and protein data in some species of deep-sea corals in Newfoundland and Labrador Region (Northwest Atlantic Ocean). Canadian Technical Report Fisheries Aquatic Science 2801: 1-18.

Hand SC, Hardewig I. 1996. Downregulation of cellular metabolism during environmental stress: mechanisms and implications. Annual Review Physiology 58: 539-563.

Hoegh-Guldberg O, Mumby PJ, Hooten AJ, Steneck RS, Greenfield P, Gomez E, Harvell CD, Sale PF, Edwards AJ, Caldeira K, Knowlton N, Eakin CM, Iglesias-Prieto R, Muthiga N, Bradbury RH, Dubi A, Hatziolos ME. 2007. Coral reefs under rapid climate change and ocean acidification. Science 318:1737-1742

Holcomb M, Cloud JG, Woolsey J, Ingermann RL. 2004. Oxygen consumption in unfertilized salmonid eggs: an indicator of egg quality? Comparative Biochemistry Physiology A: Comparative Physiology 138: 349-354.

Holcomb M, McCorkle DC, Cohen AL. 2010. Long-term effects of nutrient and CO2 enrichment on the temperate coral Astrangia poculata (Ellis and Solander, 1786). Journal Experimental Marine Biology Ecology 386: 27-33. 
Holcomb M, Cohen AL, McCorkle DC. .2012. An investigation of the calcification response of the scleractinian coral Astrangia poculata to elevated $\mathrm{pCO} 2$ and the effects of nutrients, zooxanthellae and gender. Biogeosciences 9:29-39

Jacques TG, Marshall N, Pilson MEQ. 1983. Experimental ecology of the temperate scleractinian coral Astrangia danae II. Effect of temperature, light intensity and symbiosis with zooxanthellae on metabolic rate and calcification. Marine Biology 76: 135-148.

Jokiel PL, Maragos JE, Franzisket L. 1978. Coral growth: buoyant weight technique. In: Stoddart DR, Johannes RE. eds), Coral Reefs: Research Methods. UNESCO monographs on oceanographic methodology, Paris: 529-542.

Kardish N, Ronen R, Bubrick P, Garty J. 1987. The influence of air pollution on the concentration of ATP and on chlorophyll degradation in the lichen, Ramalina duriaei (de not.) Bagl. New Phytologist 106: 697-706.

Kawaguti S, Sakumoto D. 1948. The effect of light on the calcium deposition of corals. Bull Oceanograpaical Inst Taiwan 4:65-70.

Kuhl M, Cohen Y, Dalsgaard T, Jorgensen BB, Revsbech NP. 1995. Microenvironment and photosynthesis of zooxanthellae in scleractinian corals studied with microsensors for $\mathrm{O} 2, \mathrm{pH}$ and light. Marine Ecology Progress Series 117: 159-172.

Langdon C, Atkinson MJ. 2005. Effect of elevated pCO2 on photosynthesis and calcification of corals and interactions with seasonal change in temperature/irradiance and nutrient enrichment. J Geophys Res 110:C09S07

Lannig G, Eilers S, Portner HO, Sokolova IM, Bock C. 2010. Impact of ocean acidification on energy metabolism of oyster, Crassostrea gigas--changes in metabolic pathways and thermal response. Marine Drugs 8: 2318-2339.

Larsson C-M, Olsson T. 1979. Firefly assay of adenine nucleotides from algae: Comparison of extraction methods. Plant Cell Physiology 20:145-155.

Lewis DH, Smith DC. 1971. The autotrophic nutrition of symbiotic marine coelenterates with special reference to hermatypic corals. 1. Movement of photosynthetic products between symbionts. Proceedings of the Royal Society London (B) 178:11 1-129.

Marshall AT, 1996. Calcification in hermatypic and ahermatypic corals. Science 271: 637-639.

Marshall AT, Clode PL. 2003. Light-regulated Ca2+ uptake and O2 secretion at the surface of a scleractinian coral Galaxea fascicularis. Comparative Biochemistry and Physiology 136A: 417-426.

Mass T, Einbinder S, Brokovich E, Shashar N, Vago R, Erez J, Dubinsky Z. 2007. Photoacclimation of Stylophora pistillata to light extremes: metabolism and calcification. Marine Ecology Progress Series 334: 93-102.

McCulloch M, Falter J, Trotter J, Montagna P. 2012. Coral resilience to ocean acidification and global warming through $\mathrm{pH}$ up-regulation. Nature Climate Change 2:623-627

McWilliams, J.P., Cote, I.M., Gill, J.A., Sutherland, W.J., Watkinson, A.R., 2005. Accelerating impacts of temperature-induced coral bleaching in the caribbean. Ecology 86: 2055-2060.

Mortensen PB, Rapp HT. 1998. Oxygen and carbon isotope ratios related to growth line patterns in skeletons of Lophelia pertusa (L) (Anthozoa, scleractinia): implications for determination of linear extension rates. Sarsia 83: 433-446.

Moya A, Tambutté S, Tambutté E, Zoccola D, Caminiti N, Allemand D. 2006. Study of calcification during a daily cycle of the coral Stylophora pistillata: implications for 'lightenhanced calcification'. Journal Experimental Biology 209:3413-3419

Muscatine L. 1967. Glycerol excretion by symbiotic algae from corals and tridacna and its control by the host. Science 156:516-519 
593

594

595

596

597

598

599

600

601

602

603

604

605

606

607

608

609

610

611

612

613

614

615

616

617

618

619

620

621

622

623

624

625

626

627

628

629

630

631

632

633

634

635

636

637

638

639
Nakamura T, Nadaoka K, Watanabe A. 2013. A coral polyp model of photosynthesis, respiration and calcification incorporating a transcellular ion transport mechanism. Coral Reefs 32:779794.

Oku H, Yamashiro H, Onaga K. 2003. Lipid biosynthesis from [14C]-glucose in the coral Montipora digitata. Fisheries Science 69: 625-631.

Oku H, Yamashiro H. 2003. Effect of glucose addition on the coral Montipora digitata. Sangusho ni kansuru Chosa Kenkyu Hokokusho Heisei 14 Nendo 40-45.

Pearse VB, Muscatine L. 1971. Role of symbiotic algae (Zooxanthellae) in coral calcification. Biological Bulletin 141: 350-363.

Ries JB. 2011. A physicochemical framework for interpreting the biological calcification response to CO2-induced ocean acidification. Geochimica Cosmochimica Acta 75: 40534064.

Rands ML, Douglas AE, Loughman BC, Ratcliffe RG. 1992. Avoidance of hypoxia in a cnidarian symbiosis by algal photosynthetic oxygen. Biological Bulletin 182: 159-162.

Rinkevich B, Loya Y. 1984. Does light enhance calcification in hermatypic corals? Marine Biology 80: 1-6.

Rodrigues LJ, Grottoli AG. 2006. Calcification rate and the stable carbon, oxygen, and nitrogen isotopes in the skeleton, host tissue, and zooxanthellae of bleached and recovering Hawaiian corals. Geochimica Cosmochimica Acta 70: 2781-2789.

Schneider K, Levy O, Dubinsky Z, Erez J. 2009. In situ diel cycles of photosynthesis and calcification in hermatypic corals. Limnol. Oceanogr. 54: 1995-2002.

Shashar N, Cohen Y, Loya Y. 1993. Extreme diel fluctuations of oxygen in diffusive boundary layers surrounding stony corals. Biological Bulletin 185: 455-461.

Shick JM, 1990. Diffusion limitation and hyperoxic enhancement of oxygen consumption in zooxanthellate sea anemones, zoanthids, and corals. Biological Bulletin 179: 148-158.

Smith JE, Shaw M, Edwards RA, Obura D, Pantos O, Sala E, Sandin SA, Smriga S, Hatay M, Rohwer FL. 2006. Indirect effects of algae on coral: algae-mediated, microbe-induced coral mortality. Ecology Letters 9: 835-845.

Stephens GC. 1960. Uptake of glucose from solution by the solitary coral, Fungia. Science 131: 1532.

Stephens GC. 1962. Uptake of organic material by aquatic invertebrates. I. uptake of glucose by the solitary coral, Fungia scutaria. Biological Bulletin 123: 648-659.

Stimson J, Kinzie RA III. 1991. The temporal pattern and rate of release of zooxanthellae from the reef coral Pocillopora damicornis (Linnaeus) under nitrogen-enrichment and control conditions. Journal Experimental Marine Biology Ecology 153: 63-7

Tambutté S, Holcomb M, Ferrier-Pagès C, Reynaud S, Tambutté É, Zoccola D, Allemand D. 2011. Coral biomineralization: From the gene to the environment. Journal Experimental Marine Biology Ecology 408: 58-78

Taylor DL. 1977. Intra-colonial transport of organic compounds and calcium in some atlantic reef corals. Proceedings of the 3rd International Coral Reef Symposium, 431-435.

van Heuven S, Pierrot D, Lewis E, Wallace DWR. 2009. MATLAB Program Developed for $\mathrm{CO}_{2}$ System Calculations. ORNL/CDIAC-105b. Carbon Dioxide Information Analysis Center, Oak Ridge National Laboratory, U.S. Department of Energy, Oak Ridge, Tennessee

Vandermeulen JH, Davis ND, Muscatine L. 1972. The effect of inhibitors of photosynthesis on zooxanthellae in corals and other marine invertebrates. Marine Biology 16:185-191

Vandermeulen JH, Muscatine L. 1974. Influence of symbiotic algae on calcification in reef corals: critique and progress report. In Vernberg WB, ed. Symbiosis in the Sea 1-19. 
640 Whitehead LF, Douglas AE. 2003. Metabolite comparisons and the identity of nutrients

641 translocated from symbiotic algae to an animal host. Journal of Experimental Biology 206:

$642 \quad 3149-3157$.

643 Wijgerde T, Jurriaans S, Hoofd M, Verreth JAJ, Osinga R. 2012. Oxygen and Heterotrophy Affect

644 Calcification of the Scleractinian Coral Galaxea fascicularis. PLoS ONE 7(12): e52702.

645 doi:10.1371/journal.pone.0052702

646 Yonge CM. 1931. The significance of the relationship between corals and zooxanthellae. Nature $647 \quad 128: 309-311$

648 Young SD, O'Connor JD, Muscatine L. 1971. Organic material from scleractinian coral skeletons 649 - II. Incorporation of 14C into protein, chitin and lipid. Comparative Biochemistry and 650 Physiology 40B: 945-958.

651

652 


\section{Figure 1}

\section{Effect of stir bar size}

Figure 1. Effect of stir bar size on relative calcification rates $(A)$ and oxygen consumption $(B)$ by zooxanthellate microcolonies maintained in the light or in the dark, the $40 \mathrm{~mm}$ stir bar was used as the control value for calculating relative rates. $\mathrm{N}=4$ or greater for all treatments, symbols are mean, error bars are standard deviation.

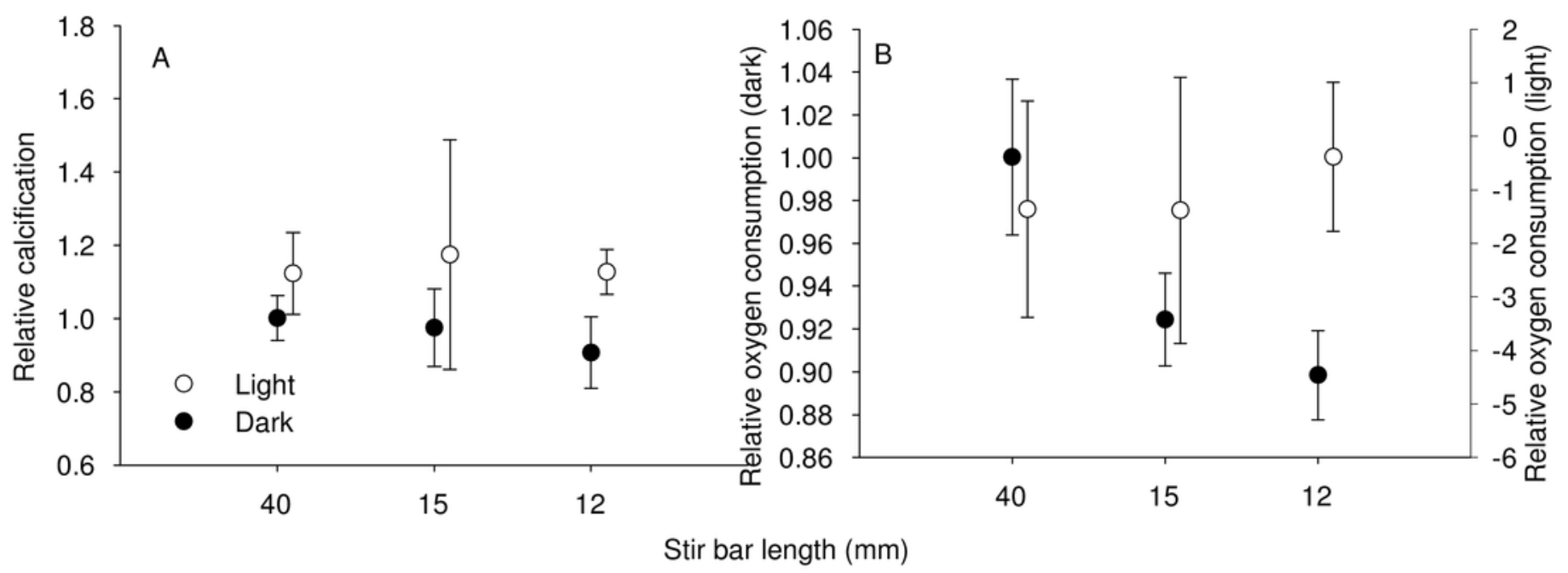




\section{Figure 2}

Relative calcification and respiration rates

Figure 2. Relative calcification $(A, C)$ and respiration $(B, D)$ rates for zooxanthellate $(A, B)$ and bleached (C, D) microcolonies maintained under each treatment condition. Treatments were: cont $=$ control, $\mathrm{ab}=$ antibiotics, $\mathrm{O} 2=\sim 2 \mathrm{x}$ atmospheric $\mathrm{pO} 2$, glu20um $=\sim 20$ uM glucose with oxygen, glu1 $\mathrm{mm}=\sim 1 \mathrm{mM}$ glucose with oxygen, gly $1 \mathrm{~mm}=\sim 1 \mathrm{mM}$ glycerol with oxygen, gly $120 \mathrm{mM}=120 \mathrm{mM}$ glycerol with oxygen, light = light. With the exception of the light treatment, all incubations were conducted in the dark. $\mathrm{N}=4$ or greater for all treatments, symbols are mean, error bars are standard deviation, ${ }^{*}=$ treatment significantly different from control at $p=0.05$.

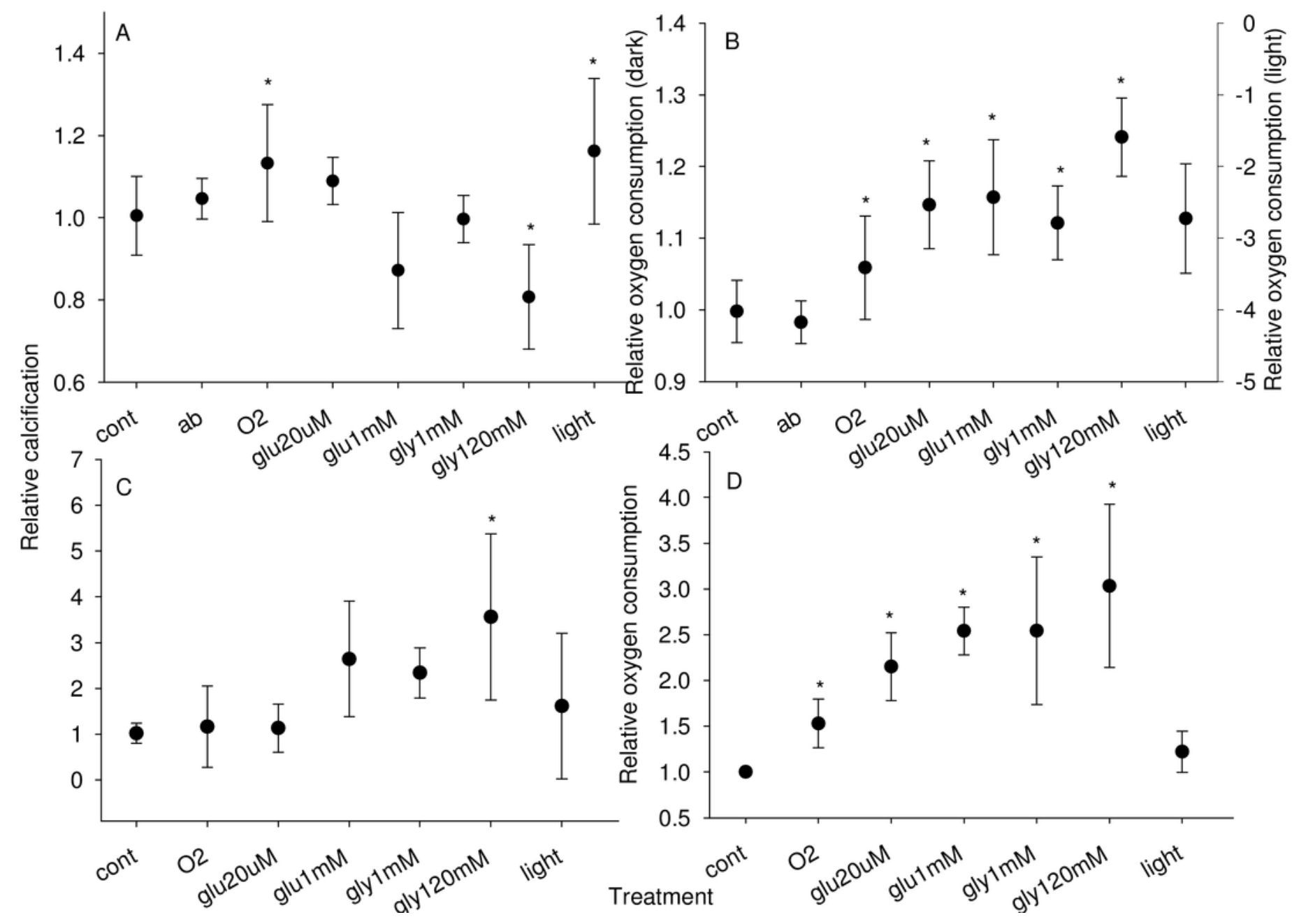




\section{Figure 3}

\section{ATP measurements}

Figure 3. ATP contents $(\mathrm{ug})$ normalized to: $\mathrm{mg}$ protein (up triangle, plotted against left axis), $\mathrm{cm} 2$ surface area (filled circles, plotted against left axis), and g skeletal dry weight (squares, plotted against the right axis) for zooxanthellate $(A)$ and bleached $(B)$ microcolonies exposed to each treatment (per Fig. 2). $\mathrm{N}=2$ or greater for all treatments, symbols are mean, error bars are standard deviation, ${ }^{*}=$ treatment significantly different from control at $p=0.05$.

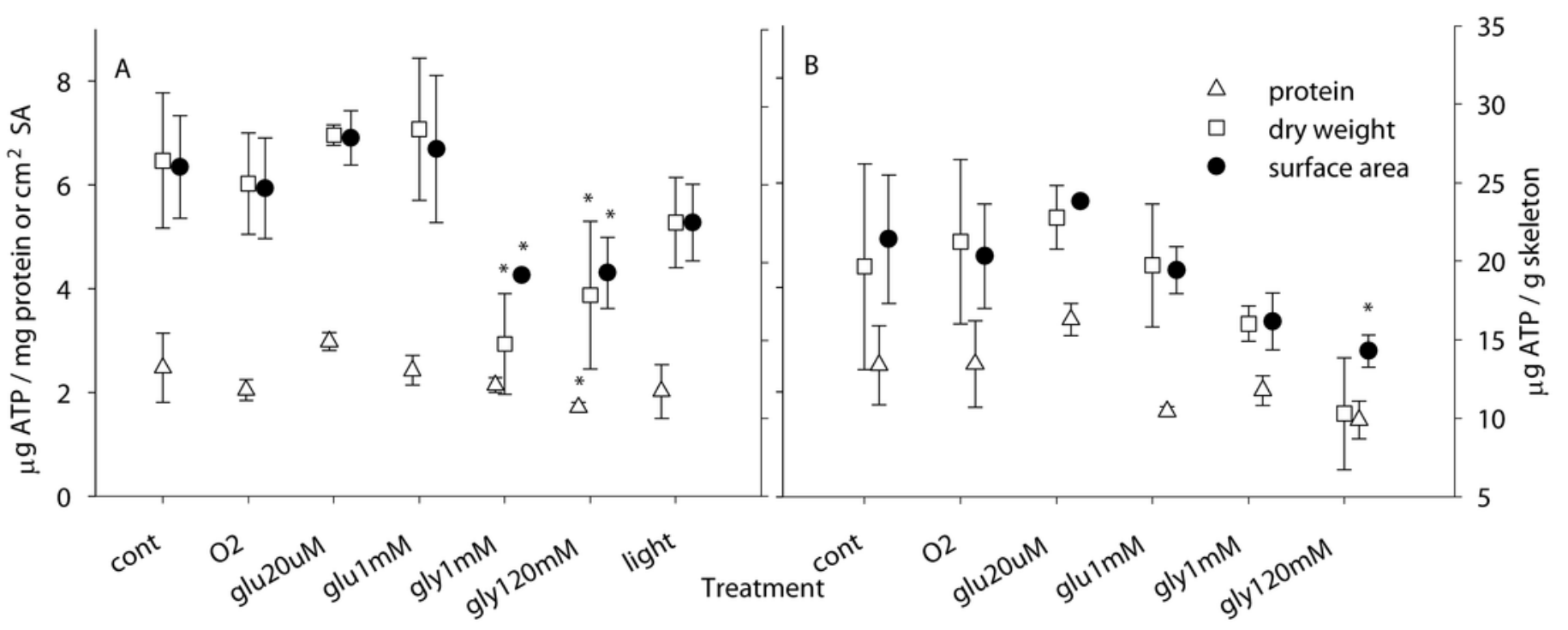

